\title{
Metformin inhibits cervical cancer cell proliferation by modulating PI3K/Akt- induced major histocompatibility complex class I-related chain A gene expression
}

\author{
Chenglai Xia ${ }^{1,2^{*}}$ D, Chang Liu ${ }^{1,3}$, Zhihong He $e^{1,3}$, Yantao Cai ${ }^{1,3}$ and Jinman Chen ${ }^{1,3}$
}

\begin{abstract}
Background: Recent studies have shown that the classic hypoglycemic drug metformin inhibits tumor growth; however, the underlying mechanism remains unclear. We previously showed that metformin disrupts the sponge effect of long non-coding RNA MALAT1/miR-142-3p to inhibit cervical cancer cell proliferation. In this study, we interrogated the ability of metformin to modulate the anti-tumor immune response in cervical cancer.

Methods: The cell counting kit-8 assay was used to detect the viability of cervical cancer cells. Flow cytometry assays were performed to measure cell apoptosis and cell cycle. Lactate dehydrogenase (LDH) cytotoxicity assay was used to detect NK Cell Cytotoxicity. Relative protein levels were determined by immunoblotting and relative gene levels were determined by quantitative real-time PCR. Tumor Xenograft Modeling was used to evaluate the effect of metformin in vivo.

Results: Metformin inhibited cervical cancer cell proliferation, cervical cancer xenograft growth, expression of PCNA, p-PI3K and p-Akt. Moreover metformin induced cervical cancer cell apoptosis and caused cancer cell cycle arrest. In addition, metformin upregulated the expression of DDR-1 and p53 in human cervical cancer cells. Furthermore, metformin also regulated the mRNA and protein expression of MICA and HSP70 on the surface of human cervical cancer cells via the PI3K/Akt pathway, enhancing NK cell cytotoxicity. Conclusions: In conclusion, our results suggest that metformin may be used as immunopotentiator to inhibit cervical cancer progression and may be considered a viable candidate for combination therapy with immunotherapy.
\end{abstract}

Keywords: Metformin, Histocompatibility complex class I-related chain a, Cervical cancer, PI3K, Cell proliferation

\footnotetext{
* Correspondence: xiachenglai@126.com

${ }^{1}$ South Medical University Affiliated Maternal \& Child Health Hospital of Foshan, Foshan 528000, China

${ }^{2}$ School of Pharmaceutical Sciences, Southern Medical University, Guangzhou 510150, China

Full list of author information is available at the end of the article
}

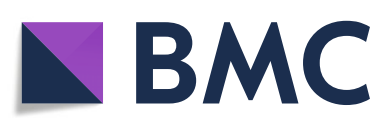

(c) The Author(s). 2020 Open Access This article is licensed under a Creative Commons Attribution 4.0 International License, which permits use, sharing, adaptation, distribution and reproduction in any medium or format, as long as you give appropriate credit to the original author(s) and the source, provide a link to the Creative Commons licence, and indicate if changes were made. The images or other third party material in this article are included in the article's Creative Commons licence, unless indicated otherwise in a credit line to the material. If material is not included in the article's Creative Commons licence and your intended use is not permitted by statutory regulation or exceeds the permitted use, you will need to obtain permission directly from the copyright holder. To view a copy of this licence, visit http://creativecommons.org/licenses/by/4.0/. The Creative Commons Public Domain Dedication waiver (http://creativecommons.org/publicdomain/zero/1.0/) applies to the data made available in this article, unless otherwise stated in a credit line to the data. 


\section{Background}

According to the tumor data reported in 2019, nearly 529,000 newly diagnosed cases of cervical cancer are reported annually and the mortality of cervical cancer ranks the second in 20- to 39-year-old female cancer patients, with approximately nine cancer patients die of cervical cancer each week [1]. Cervical cancer is generally treated by surgery, chemotherapy, or radiotherapy alone or in combination [2]. However, the survival rate of cervical cancer patients remains relatively low. Although the 2-, 4-, and 9-valent human papillomavirus (HPV) vaccines have been shown to prevent cervical cancer, these do not have protective effects on all individuals $[3,4]$. Hence, the development of novel treatments to inhibit tumor invasion and migration and improve the survival rate and quality of life of cervical cancer patients is particularly important.

Metformin is currently the first-line oral drug for the treatment of type 2 diabetes; it is inexpensive and imparts a significant therapeutic effect. Studies have shown that diabetic patients with metformin treatment have a lower incidence of cancer. The antitumor effect of metformin is closely related to mechanistic target of rapamycin complex 1 (mTORC1), a key protein of the PI3K/ Akt/mTOR pathway [5-8]. Studies have shown that phosphatidylinositol 3-kinase (PI3K), epidermal growth factor receptor, extracellular signal-regulated kinases, anti-apoptotic B-cell lymphoma 2 (Bcl-2) pathways and proteins play an important role in the development of tumors, particularly solid tumors such as cervical cancer $[9,10]$. These signaling pathways and proteins form the regulatory network of cervical cancer and are ideal targets for the development of antitumor drugs. The PI3K/ serine-threonine kinase/rapamycin pathway has recently been shown to be closely related to the growth and proliferation of solid tumor cells, and serine/threonine kinases play a central role in the pathway. PI3K inhibitors inhibit the expression of downstream serine/threonine kinases. In addition, serine/threonine kinase inhibitors suppress tumor cell proliferation $[11,12]$.

Natural killer (NK) cells are important immune cells in the body that are involved in antitumor, antiviral infection, and immunomodulation processes. Under specific conditions, NK cells can identify target cells and activate immune cells. NK cells impart broad spectrum antitumor effects and do not show specificity or major histocompatibility complex (MHC) restriction. NK cells have two anticancer effects. First, NK cells can directly kill tumor cells by releasing perforin and granzymes or by death receptor engagement. Second, NK cells can secrete cytokines and chemokines to activate $\mathrm{T}$ cells and exert a killing effect [13]. Studies have shown that valproic acid (VPA) upregulates the expression of human histocompatibility complex class I-related chain A
$(M I C A)$ and histocompatibility complex class I-related chain $\mathrm{B}(M I C B)$ by activating PI3K/Akt signaling [14, 15]. The NK group 2D (NKG2D) receptor is an activated receptor for MICA on NK cells that recognizes $\mathrm{MHC}$ class I molecules and plays an important role in innate immunity. When MICA on the surface of tumor cells is activated, NK cells can recognize the MICA and initiate the antitumor immune response $[16,17]$. In vitro studies have shown that peripheral blood NK cells (PBNK) are able to kill HPV-infected cell lines [18]. However, NK cells are often dysfunctional and low in number in cervical cancer patients and thereby unable to mount efficient cytotoxicity against tumors [19].

Our previous study has shown that metformin disrupts the sponge effect of long non-coding RNA MALAT1/ miR-142-3p to activate the expression of the downstream antitumor protein high-mobility group A protein 2 (HMGA2) and exert an anti-cervical cancer effect [20]. We also found that a combination treatment with metformin and nelfinavir for $12 \mathrm{~h}$ significantly upregulated MICA protein expression in SiHa and HeLa cells [21]. However, the molecular mechanism by which metformin upregulates MICA remains unclear. This study aimed to elucidate the molecular mechanisms by which metformin activates antitumor immunity.

\section{Materials and methods}

\section{Cells, reagents, and antibodies}

In this study, the human cervical cancer cell lines, $\mathrm{SiHa}$ cells and HeLa cells, and the NK-92 cells were from a research laboratory of Foshan Maternity and Child Health Care Hospital, Guangdong Province, China. The $\mathrm{SiHa}$ and HeLa cells were cultured in Dulbecco's modified eagle medium (DMEM) containing 10\% fetal bovine serum (Invitrogen, Carlsbad, CA, USA) and 1\% streptomycin (Sigma-Aldrich, St. Louis, MO, USA). The NK-92 cells were cultured in alpha-minimum essential medium (a-MEM) containing $100 \mathrm{U} / \mathrm{mL}$ interleukin (IL)-2. Dimethyl sulfoxide (DMSO), LY294002, and metformin hydrochloride were purchased from Sigma-Aldrich. Anti-MICA, anti-MICB, anti-ULBP-2/5/6 Phycoerythrin, anti-ULBP-1 Alexa Fluor 488, anti-ULBP-3 Allophycocyanin, anti-DDR-1, anti-HSF-1, anti-PI3K (110a), antiphospho-PI3Kp55 (Tyr199), anti-Akt, anti-phospho-Akt (ser473), anti- proliferating cell nuclear antigen (PCNA), anti-p53 primary antibodies, and their corresponding secondary antibodies were purchased from Cell Signaling Technology (Beverly, MA, USA).

\section{Analysis of cell proliferation}

According to the methods described in a previous study [22], cells were trypsinized and seeded in 96-well plates $\left(1 \times 10^{4}\right.$ cells per well). After the cells were attached, metformin was added at various concentrations (0- 
$400 \mu \mathrm{M})$ for $48 \mathrm{~h}$. To analyze cell viability, the cell proliferation assay, cell counting kit-8 (CCK-8), was used to measure the absorbance of the samples using a microplate reader and at a wavelength of $450 \mathrm{~nm}$.

\section{Cell apoptosis assays}

According to the methods described in a previous study [8], Cervical cancer cell lines (HeLa and $\mathrm{SiHa}$ ) were seeded at a density of $2 \times 10^{5}$ cells/well in a 6-well culture plate. The cells were washed twice with cold PBS, and then resuspended in $1 \times$ binding buffer. One hundred $\mu \mathrm{l}$ of the cell suspension $\left(1 \times 10^{5}\right.$ cells $)$ was transferred to a $5 \mathrm{ml}$ culture tube and mixed with $5 \mu \mathrm{l}$ of FITC anti-Annexin V and $5 \mu \mathrm{l}$ PI. The mixture was gently vortexed and incubated for $15 \mathrm{~min}$ at $\mathrm{RT}\left(25^{\circ} \mathrm{C}\right)$ in the dark. Then, $400 \mu \mathrm{l}$ of $1 \times$ binding buffer was added into each tube. The samples were analyzed by flow cytometry within $1 \mathrm{~h}$. The green fluorescence of Annexin V-FITC was measured at $530 \mathrm{~nm}$, and the red fluorescence of PI was measured at $585 \mathrm{~nm}$. The results were analyzed with FlowJo software.

\section{Cell cycle assays}

Cells were harvested in PBS and fixed by addition of icecold $70 \%$ ethanol with a Pasteur pipette during vortexing, as previously described [8]. Then, the cells were centrifuged at approximately $2000 \mathrm{rpm}$ for $5 \mathrm{~min}$ and washed twice with PBS. Finally, the cell were stained by PI staining solution (Invitrogen) and analyzed by flow cytometry collecting 25,000 events per sample. The results were analyzed with FlowJo software.

\section{Nuclear protein extraction}

According to the methods described in a previous study [23], cells were washed three times with pre-cooled phosphate buffered saline (PBS) and subsequently scraped off with a cell scraper and collected in a $1.5 \mathrm{~mL}$ centrifuge tube. The cells were centrifuged at $1000 \mathrm{rcf}$, $4{ }^{\circ} \mathrm{C}$, for $3 \mathrm{~min}$. A protease inhibitor, cell lysis buffer, and cell membrane rupture solution were added into the pellet to lyse the cells on ice for $1 \mathrm{~h}$, followed by $1000 \mathrm{rcf}$ centrifugation at $4{ }^{\circ} \mathrm{C}$ for $20 \mathrm{~min}$. The supernatant was discarded, and the pellet was then lysed with nuclear extraction lysis buffer on ice for $1 \mathrm{~h}$, with vortexing every $5 \mathrm{~h}$ for complete lysis, which was followed by $12,000 \mathrm{rcf}$ centrifugation at $4{ }^{\circ} \mathrm{C}$ for $15 \mathrm{~min}$ to collect the supernatant (i.e., nuclear protein extract).

\section{Lactate dehydrogenase (LDH) cytotoxicity assay}

As described in the methods of a previous study [21, $23]$, the human cervical cancer HeLa or $\mathrm{SiHa}$ cells were seeded as target cells in 96-well plates $\left(2 \times 10^{4}\right.$ cells per well) in a total volume of $100 \mu \mathrm{L}$ per well. The cells were then divided into five different groups as follows: drug treatment; effector cells (NK-92) with spontaneous LDH efflux; target cells with spontaneous LDH efflux; target cells with maximum LDH efflux; and volume correction (no cells) groups. Approximately $10 \mu \mathrm{L}$ of lysis buffer (10x) was added to each well of cells and then incubated in a $37^{\circ} \mathrm{C}$ incubator with $5 \% \mathrm{CO}_{2}$ atmosphere. After $250 \times g$ centrifugation for $3 \mathrm{~min}, 50 \mu \mathrm{L}$ of a reaction solution were added to each well of the 96-well plates, followed by $50 \mu \mathrm{L}$ stopping solution, with gentle mixing, and then the absorbance at wavelengths of $490 \mathrm{~nm}$ and $680 \mathrm{~nm}$ were read. The cytotoxicity of different target ratios (\%) was calculated using the following formula: Cytotoxicity $(\%)=($ Experimental group - Effector cells with spontaneous LDH efflux group - Target cells with maximum LDH efflux group)/(Target cells with maximum LDH efflux group - Target cells with spontaneous LDH efflux group) $\times 100$.

\section{RNA extraction and quantitative real-time PCR}

According to the methods described in a previous study [20], After transfection for $48 \mathrm{~h}$, total RNA was isolated from $\mathrm{SiHa}$ and HeLa using TRIzol reagent (TAKARA, Dalian, China) according to the manufacturer's instructions. For mRNA quantification, RNA was reverse transcribed into cDNA using the PrimeScript ${ }^{\mathrm{Tw}}$ RTreagent Kit (Takara, Japan) and then quantified on the CFX96 touch q-PCR system (BIO-RAD, USA) with SYBR Premix Ex Taq Kit (Takara, Japan) according to the manufacturer's protocols. In this study, GAPDH was used as an internal control for determining the levels of HSP70 and MICA. The primers used for quantitative real-time polymerase chain reaction (qRT-PCR) are listed in Table 1. Reactions were performed using a SYBR Green kit (TAKARA, Dalian, China), according to the manufacturer's instructions. Each $20-\mu \mathrm{l}$ reaction mixture included $2 \mu \mathrm{l}$ of cDNA, $10 \mu \mathrm{l}$ of SYBR Green Mix, $0.4 \mu \mathrm{l}$ of forward primer, $0.4 \mu \mathrm{l}$ of reverse primer, $0.4 \mu \mathrm{l}$ of RoxReference Dye, and $6.8 \mu \mathrm{l}$ of RNase-free water. Then, the PCR reactions were performed in the CFX96 touch q-PCR system (BIO-RAD, USA) under the following conditions: $95^{\circ} \mathrm{C}$ for $30 \mathrm{~s}$, followed by 40 cycles at $95^{\circ} \mathrm{C}$ for $5 \mathrm{~s}, 60^{\circ} \mathrm{C}$ for 30 $\mathrm{s}, 95^{\circ} \mathrm{C}$ for $15 \mathrm{~s}$, and $60^{\circ} \mathrm{Cfor} 60 \mathrm{~s}$. Relative gene expression was determined by using the $\Delta \Delta \mathrm{C}_{\mathrm{t}}$ method. Significance was defined according to $P$ values from the two-tailed $\mathrm{t}$ test. All of the reactions were performed in triplicate.

\section{Western blotting}

Western blotting was performed as previously described [24]. Briefly, the cells were harvested and lysed with RIPA lysis buffer, and the concentration of the collected proteins was determined. Then, $100 \mu \mathrm{g}$ of the extracted protein was separated in $10,8 \%$, or $5 \%$ SDS-PAGE gel based on the molecular weight of the target protein. The separated protein gel with a pre-stained protein marker 
Table 1 Oligonucleotide primer sequences for qRT-PCR

\begin{tabular}{cc}
\hline Gene & Primers(5'-3') \\
\hline \multirow{2}{*}{ MICA } & F:5'-AGG GCT TCT GGC TTC TAT CC-3' \\
& R:5'-AGG GCT TCT GGC TTC TAT CC-3' \\
GAPDH & F:5'-CGC TGA GTA CGT CGT GGA GTC-3' \\
& R:5'-GCT GAT GAT CTT GAG GCT GTT GTC-3' \\
HSP70 & F:5'-TAC TGT GGA CCT GCC AAT CG -3' \\
& R:5'-TAG CAT CAT TCC GCT CCT TC-3 \\
\hline
\end{tabular}

was transferred onto a PVDF membrane. Subsequently, the membrane was blocked in a $5 \%$ skim milk solution at room temperature for $2 \mathrm{~h}$, followed by incubating with the corresponding primary and secondary antibodies and washing with Tris-buffered saline, $0.1 \%$ Tween 20 (TBST) in between. The PVDF membrane was developed using an enhanced chemiluminescence solution (Pierce) and subsequently photographed in a Bio-Rad gel imaging system. The exposure time was adjusted according to the protein bands and background. After selecting the clear protein bands in the image, the gray value of each protein band was analyzed by software and statistical analysis was conducted.

\section{Tumor Xenograft modeling and in vivo experiments}

BALB/c nude mice of 4 weeks old (weighing approximately 15-17 g) were purchased from Guangdong Medical Laboratory Animal Center (Guangdong Province, China). All mice were housed and bred in a specificpathogen-free (SPF) grade animal facility, with $22-25^{\circ} \mathrm{C}$ temperature, $40-60 \%$ humidity, and $12 \mathrm{~h} / 12 \mathrm{~h}$ light/dark cycle. To generate tumor xenograft, 20 mice were used. The skin of the left forelimb near the armpit was disinfected and $0.1 \mathrm{~mL} \mathrm{SiHa}$ cells suspended in serum-free medium (containing approximately $5 \times 10^{6}$ cells) were injected. After inoculation of the cervical cancer cells, the nude mice were continuously housed under the same conditions. Once the subcutaneous nodules grown to a rice grain size (required approximately a week), the subcutaneous xenograft model of cervical cancer in nude mice was successfully constructed. The subcutaneous tumor size in each nude mouse was measured using a digital vernier caliper. Once the tumor diameter reached approximately $0.3-0.5 \mathrm{~cm}$, the nude mice were numbered, randomly divided into four groups (with five mice per group), namely, control, model, $50 \mathrm{mg} / \mathrm{kg} / \mathrm{d}$ metformin, and $250 \mathrm{mg} / \mathrm{kg} / \mathrm{d}$ metformin groups. Metformin was given by gavage. All nude mice were closely monitored for tumor growth, skin condition, and behavior daily and any tumor ulceration or irritation was noted. The longest (A) and the shortest (B) diameters of the subcutaneous tumors were measured with a digital vernier caliper before each metformin administration to calculate the tumor volume $(\mathrm{V})$ using the following formula: $\mathrm{V}=0.5 \times \mathrm{A} \times \mathrm{B}^{2}$. In addition, all nude mice were weighed daily, and their daily food intake was also measured. After the completion of the 23-day metformin administration, all nude mice were sacrificed and placed on ice, their skin was immediately cut open, and the subcutaneous tumor xenografts were collected. After weighing each tumor xenograft on a digital scale, one part of the tumor tissue was dissected and frozen in liquid nitrogen for western blotting. All experimental procedures were approved by the Institutional Animal Care and Use Committee of South Medical University.

\section{Statistical analysis}

The SPSS16.0 software (IBM SPSS, Chicago, IL, USA) was used for data analysis in this study. An independent $\mathrm{T}$ test was used to compare the results between the two groups. Multivariate ANOVA was used to compare differences between multiple groups, followed by multiple corrections using the Bonferroni's test. $P<0.05$ was considered statistically significant.

\section{Results \\ Metformin inhibits the proliferation of cervical Cancer cells}

Similar to other tumors types, cervical cancer cells have infinite proliferative properties [25]. Inhibition of tumor cell proliferation has been one of the strategies for developing chemotherapy drugs. Here, metformin was used to treat cervical cancer cells for $72 \mathrm{~h}$, and CCK- 8 was used to evaluate the effect of metformin on cervical cancer cell proliferation. The IC50 value of metformin was $25.13 \pm 0.99 \mathrm{mM}$ and $19.43 \pm 1.41 \mathrm{mM}$ in HeLa cells and SiHa cells, respectively (Fig. 1a). Metformin also inhibited cervical cancer cell proliferation in a timedependent manner, when cervical cancer lines were treated with metformin for $24 \mathrm{~h}, 48 \mathrm{~h}$ and $72 \mathrm{~h}$ (Fig. 1b). PCNA is a molecular marker of cell proliferation and is commonly used in evaluating cell growth status (Branca et al., 2007). Detection of PCNA in the nuclear protein extracts of $\mathrm{SiHa}$ and $\mathrm{HeLa}$ cells by western blot 


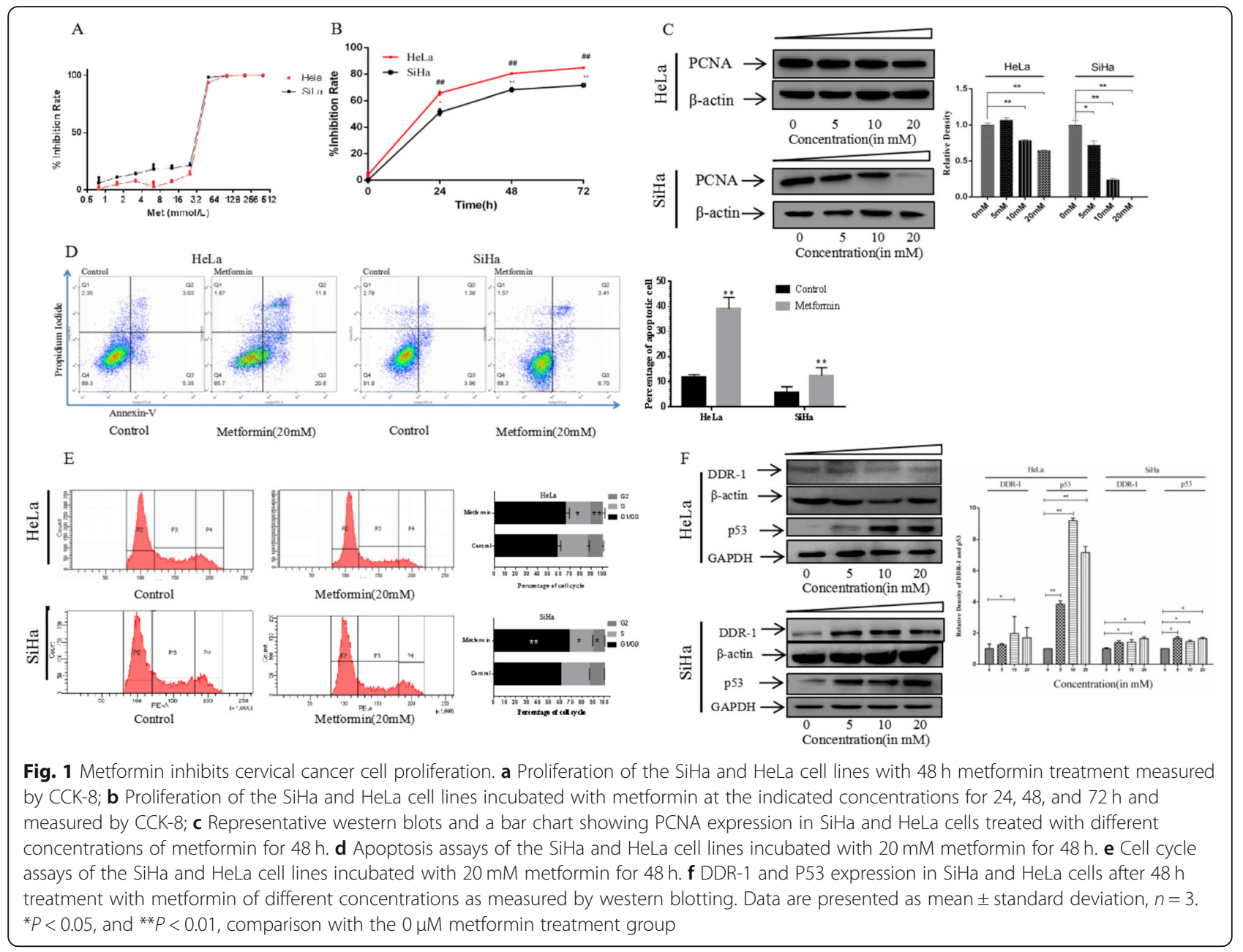

indicated a decrease in PCNA following treatment with metformin at $5 \mathrm{mM}, 10 \mathrm{mM}$, and $20 \mathrm{mM}$ (Fig. 1c).

Promoting cancer cells apoptosis is a characteristics of chemotherapy drugs. In our present study, we used flow cytometry to detect the effect of metformin on inducing cervical cancer apoptosis. As shown in Fig. 1d, the apoptosis ratio of HeLa cells increased from $11.61 \pm 0.47 \%$ to $39.04 \pm$ $1.88 \%$ and the apoptosis ratio of $\mathrm{SiHa}$ cells increased from $5.69 \pm 1.02 \%$ to $12.31 \pm 1.63 \%$ when these cells were treated with $20 \mathrm{mM}$ metform for $48 \mathrm{~h}$. Inducing cancer cell cycle arrest is another characteristics of chemotherapy drugs. In our present study, we also used flow cytometry to measure the effect of metformin on causing cervical cancer cell cycle arrest. As shown in Fig. 1e, the percentage of G0/G1 phase cells increased and the percentage of $\mathrm{S}$ phase cells decreased when HeLa and $\mathrm{SiHa}$ cells were treated with $20 \mathrm{mM}$ metform for $48 \mathrm{~h}$.

P53 protein is an important regulator of cell proliferation and inhibits HPV E6 protein-induced ubiquitination of proteasome to exert the antitumor effect [26, 27]. Discoidin domain receptor 1 (DDR1) is a collagen binding receptor and also act as an activator of p53 in cancer cell proliferation processes [28]. In this study, $\mathrm{SiHa}$ and HeLa cells were treated with varying concentrations of metformin for $48 \mathrm{~h}$, followed by western blotting to assess DDR-1 and p53 expression. As metformin concentration increased from $5 \mathrm{mM}$ to $20 \mathrm{mM}$, the expression of DDR-1 and p53 protein increased in the cervical cancer cell lines. Metformin upregulated DDR-1 expression activating p53 in the tumor cells in a dose-dependent manner (Fig. 1f). These results suggest that metformin increased DDR-1 expression along with p53 activated to inhibit the proliferation of cervical cancer cells. Taken together, these results indicate that metformin decreased cervical cancer cell proliferation.

\section{Metformin Upregulates MICA and HSP70 expression to increase the sensitivity of tumor cells to NK cell cytotoxicity}

Tumor immune escape is an important feature of tumor invasion and metastasis [25]. Restoring the sensitivity of the body to tumor immune escape is the main means to cancer immunotherapy. MICA is a membrane protein that is involved in anti-infective immunity and antitumor 
immunity. MICA expression on the tumor cell surface is usually low [29]. When MICA protein is activated on the tumor cell surface, MICA binds to its ligand, NKG2D, on the surface of NK cells to enhance the killing effect of NK cells on tumors [30, 31]. Furthermore, all the other NKG2D ligands, MICB and ULBPs (1 to 6), are also binds to NKG2D to show their antitumor immunity [32].

HSP70 is a common molecular chaperone that is expressed in the membranous organelles of all cells. It is mainly involved in protein synthesis and processing [3335]. Under normal circumstances, HSP70 expression is relatively low; however, under the conditions of protein damage caused by heat shock and hypoxia, HSP70 protein may be regulated by the PI3K/AKT/NRF2 pathway, and its expression is increased [36, 37]. A previous study has shown that HSP70 plays a synergistic role with immune cells in antitumor immunity [38]. Moreover, heat shock factor 1 (HSF-1), one of the best known activators of HSP70 expression, is also an activator of the MICA gene promoter [39]. Therefore, we assessed HSF-1, HSP70 and MICA expression in cervical cancer cells after metformin treatment and also investigated the sensitivity of NK-92 cells to cancer cells. We also evaluated all the other NKG2D ligands expression in the surface of cervical cancer cells. As shown in Fig. 2a and b, metformin increased HSF-1, MICA and HSP70 protein expression in $\mathrm{SiHa}$ and HeLa cells and also induced MICA expression on the surface of human cervical cancer cells. However, metformin did not induce MICB, ULBP1, ULBP2/5/6 and ULPB3 expression on the surface of human cervical cancer cells (Fig. 2b). In addition, the mRNA expression of HSP7O gene and MICA gene increased in $\mathrm{SiHa}$ and HeLa cells when treated with metformin (Fig. 2c).

We further assessed LDH efflux in the SiHa and HeLa cells and evaluated the effect of metformin on NK cellmediated killing of human cervical cancer cells. Varying concentrations of metformin treatment $(5 \mathrm{mM}, 10 \mathrm{mM}$, and $20 \mathrm{mM}$ ) increased the NK-92 cell lethality to SiHa and HeLa cells from $37.45 \pm 0.64 \%$ to $40.45 \pm 0.71(\mathrm{SiHa})$ and from $49.04 \pm 0.32 \%$ to $86.00 \pm 2.24 \%$ (HeLa), respectively, in a dose-dependent manner (Fig. 2d, Table 2). These results suggest that metformin induces MICA and HSP70 expression on the surface of human cervical cancer cells. Additionally, an increase in MICA expression enhanced NK cell cytotoxicity.

\section{Metformin increases MICA expression via the PI3K/Akt pathway}

Studies have shown that metformin inhibits the invasion and metastasis of tumor cells and induces degradation of cyclin D1 through AMP-activated protein kinase/glycogen synthase kinase 3 beta (AMPK/GSK3 $\beta$ ) signaling axis to participate in the protein ubiquitination process [40]. To further elucidate the molecular mechanism by which metformin inhibits the proliferation of cervical cancer cells, SiHa and HeLa cells were treated with varying concentrations of metformin $(0 \mathrm{mM}, 5 \mathrm{mM}, 10 \mathrm{mM}$, and $20 \mathrm{mM}$ ) for $48 \mathrm{~h}$, followed by western blotting to detect PI3K (p110), p-PI3K p85 (Tyr199), Akt, and p-Akt (ser473) protein expression. As the concentration of metformin increased, the expression of p-PI3K p85 (Tyr199) and p-Akt (ser473) decreased (Fig. 3a). When PI3K/Akt signaling was blocked with the PI3K/Akt signaling inhibitor, LY294002, the inhibitory effect of metformin on the p-PI3K p85 (Tyr199) and p-Akt (ser473) was enhanced (Fig. 3b). In addition, after using the LY294002 to block the PI3K/Akt signaling, the induction of MICA by metformin also increased, whereas LY294002 had little effect on HSP70 expression (Fig. $3 c)$. Because metformin targets AMPK signaling and the target of LY294002 is $\mathrm{PI} 3 \mathrm{Ka} / \delta / \beta$ [41], these different pathways may act synergistically, whereas compounds with the same targets may have antagonistic effects. These results indicate that metformin inhibits tumor cell proliferation by increasing the expression of MICA protein on the tumor cell surface via disrupting the PI3K/ Akt pathway.

\section{Metformin inhibits the growth of cervical Cancer Xenograft in a nude mouse model}

Tumor cell line-derived xenograft animal modeling has been extensively used in antitumor drug screening and evaluation because such models are easy to construct, the tumor formation rate is high, and the experimental cycle is short [8]. In this study, $\mathrm{SiHa}$ cells were used to develop a cervical cancer xenograft model in BALB/C nude mice to study the inhibitory effect of metformin on tumor growth. After successful modeling, $50 \mathrm{mg} / \mathrm{kg} / \mathrm{d}$ and $250 \mathrm{mg} / \mathrm{kg} / \mathrm{d}$ metformin were administered (by oral gavage) to mice bearing cervical cancer xenografts for 23 consecutive days (Fig. 4). Compared to the model group, the mice in the $250 \mathrm{mg} / \mathrm{kg} / \mathrm{d}$ metformin treatment group exhibited slower tumor growth. Assessment of PI3K (p110), p-PI3K p85 (Tyr199), Akt, p-Akt (ser473), MICA, HSP70 and p53 expression in the tumor xenografts showed that xenografts of the $250 \mathrm{mg} / \mathrm{kg} / \mathrm{d}$ metformin treatment group had significantly lower p-PI3K p85 (Tyr199) and p-Akt (ser473) levels, whereas the MICA, HSP70, and p53 expression in the xenografts of the $250 \mathrm{mg} / \mathrm{kg} / \mathrm{d}$ metformin treatment group was significantly higher, compared to the model group. These results suggest that metformin inhibits p-PI3K p85 (Tyr199) and p-Akt (ser473) expression; upregulates MICA and p53 expression; and inhibits the growth of cervical cancer xenografts in mice. 


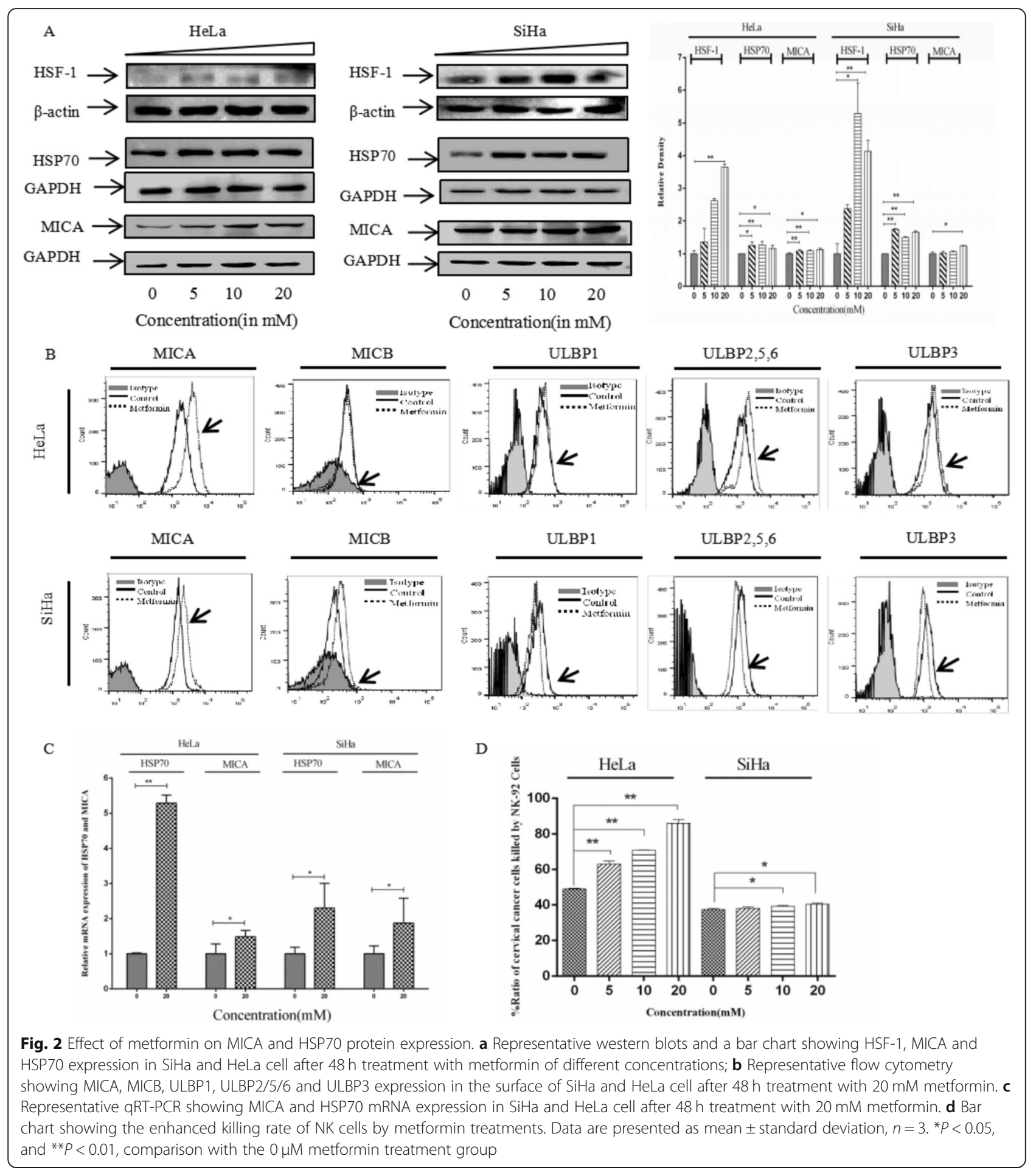

\section{Discussion}

Classic drug design strategies generally target a single protein or signaling pathway. However, the pathogenesis of most diseases, including cancers, is complex. Thus, it is necessary to develop drugs that target multiple proteins and disease-related signaling pathways. Metformin, a biguanide blood sugar-reducing agent, has been extensively used in clinical practice because of its safety and efficacy profile, as well as being inexpensive. Studies have shown that metformin can target one or more signaling pathways to inhibit tumor cell proliferation, invasion, and migration [42]. For example, metformin directly activates the AMPK pathway and reduces insulin-like growth factor 1 (IGF-1) expression to inhibit 
Table 2 Ration of cervical cancer cells killed by NK-92 cells with different concentrations of metformin

\begin{tabular}{ccc}
\hline \multirow{2}{*}{$\begin{array}{c}\text { Concentrations of Metformin } \\
(\mathrm{mM})\end{array}$} & \multicolumn{2}{c}{ \% the killed cervical cancer cells } \\
\cline { 2 - 3 } & HeLa & SiHa \\
\hline 0 & $49.04 \pm 0.32$ & $37.45 \pm 0.64$ \\
50 & $63.11 \pm 1.71^{\text {**** }}$ & $38.02 \pm 0.91$ \\
100 & $70.90 \pm 0.18^{* * * *}$ & $39.25 \pm 0.47^{*}$ \\
200 & $86.00 \pm 2.24^{* * * *}$ & $40.45 \pm 0.71^{*}$ \\
\hline$(* \mathrm{p}<0.05 ; * * \mathrm{p}<0.01 ; \mathrm{vs} 0 \mathrm{mM}, \mathrm{n}=3)$ &
\end{tabular}

insulin signaling, block the glucose metabolism pathway of tumor, and exert antitumor effect $[43,44])$. A recent study identified AMPK O-GlcNAcylation as antiproliferative mechanism of metformin in cervical cancer [45]. Since HeLa cells do not express LKB1 (which phosphorylates AMPK) [46], it is shown in some studies that this cell line might be resistant to metformin [47]. However, metformin exhibits a complex anti-tumor mechanism for its small molecular weight (MW: 165.6 )[48, 49]). In this study, we found that metformin inhibits cervical cancer cell proliferation in a dose-dependent manner through non-AMPK signaling pathways.

P53 is a tumor suppressor. More than 50\% of all malignant tumors have $p 53$ mutation. The protein encoded by $p 53$ gene is a transcriptional factor called TP53 that controls the initiation of cell cycle. P53 protein is mainly distributed in the nucleoplasm of cells and specifically binds to DNA. Its activity is regulated by posttranslational modification, such as phosphorylation, acetylation, methylation, and ubiquitination [26, 50]. Normal p53 acts as the "guardian of the genome," screening for sites of DNA damage in the G1 phase and monitoring the integrity of the genome. In the event of DNA damage, p53 prevents DNA replication to provide sufficient time for the repair of the damaged DNA. It triggers apoptosis if the repair of the damaged DNA fails. During the cell cycle, p53 mainly functions in the monitoring of the G1 and G2/M phase check points, and this function is closely related to transcriptional activation. Discoidin domain receptor 1 (DDR1) can activate p53 by binding its receptor. In our present study, we showed the evidence that metformin upregulated DDR-1 expression inhibiting the proliferation of cervical cancer cells, promoting cervical cancer apoptosis and suppress cervical cancer xenograft tumor tissues growth in a dosedependent manner along with activating p53.
MICA is a member of the MHC class I molecular family and is expressed on the cell surface membranes. Recent research has shown that MICA is associated with the development of a variety of tumors. It is a stress marker and is expressed in pathogenic bacteria, tumors, and organ transplant recipients [30]. MICA is the receptor of NKG2D, an important activating protein on the NK cell surface, and NK cells play a very important role in tumor innate immunity to kill tumor cells by recognizing tumor cell surface markers and producing a cytotoxic effect [51]. Previous studies have shown that high glucose protects pancreatic cancer from NK cellmediated killing through suppressing MICA/B expression. Moreover, high glucose inhibited AMP-activated protein kinase signaling, leading to high expression of Bmi1, a polycomb group (PcG) protein which was found to be up-regulated by high glucose, and mediated the inhibition of $\mathrm{MICA} / \mathrm{B}$ expression through promoting GATA2 in pancreatic cancer [52]. AMP-activated protein kinase (AMPK)-histone deacetylase 5 (HDAC5) pathway promoted nuclear accumulation of HIF-1a and functional activation of HIF-1 by deacetylating heat shock protein $70(\mathrm{HSP} 70)$ in the cytosol, indicating a novel link between AMPK, HIF-1a, and HSP70 [53]. HSP70 is not immunogenic but can participate in antigen processing after binding to polypeptides and enhance the immune response. A clinical trial injected purified HSP70 into children with brain cancer and found an antitumor effect and certain feasibility and safety in the antitumor therapy [54, 55]. Another study has also shown that HSP70 inhibits brain tumor development in a C6 glioblastoma mouse model, which is associated with NK cell and T lymphocyte killing abilities of glioblastoma, as well as increased activities of NK cells and $\mathrm{CD} 81^{+} \mathrm{T}$ lymphocytes [55]. In the present study, we found that metformin increased HSF-1, MICA and HSP70 protein expression in $\mathrm{SiHa}$ and HeLa cells and 


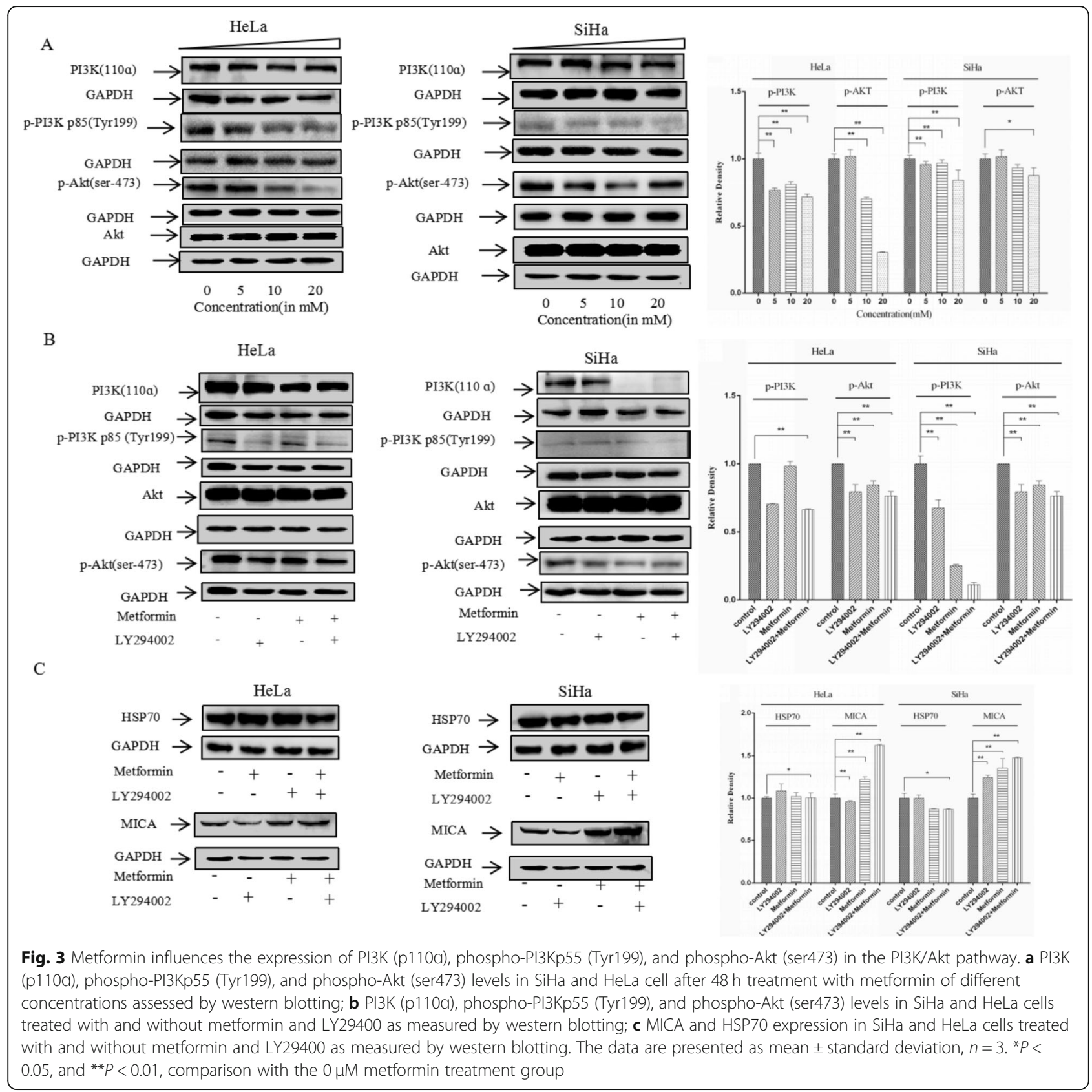

also induced MICA expression on the surface of human cervical cancer cells. However, metformin did not induce MICB, ULBP1, ULBP2/5/6 and ULPB3 expression on the surface of human cervical cancer cells. In addition, the mRNA expression of HSP7O gene and MICA gene increased in $\mathrm{SiHa}$ and HeLa cells when treated with metformin. We concluded that metformin activated NK cells by regulating MICA though a transcription mechanism to mediate innate immunity. As an immunopotentiator, merformin could upregulate HSF-1, one of the best known activators of HSP70 expression, to activate
HSP70 and is involved in specific immune activation in the nude mice and exerted antitumor effect.

In the classic PI3K/Akt/mTOR pathway, PI3K is a family of many lipid kinases consisting of a regulatory subunit, p85, and a catalytic subunit, p110. When a ligand binds to the membrane receptor, the receptor activates p53 and recruits p110, thereby catalyzing the formation of phosphatidylinositol 3-phosphate (PI3P) by phosphatidylinositol 4, 5-bisphosphate (PIP2) on the inner surface of the membrane. PI3P, as a second messenger, further activates Akt and phosphoinositide- 


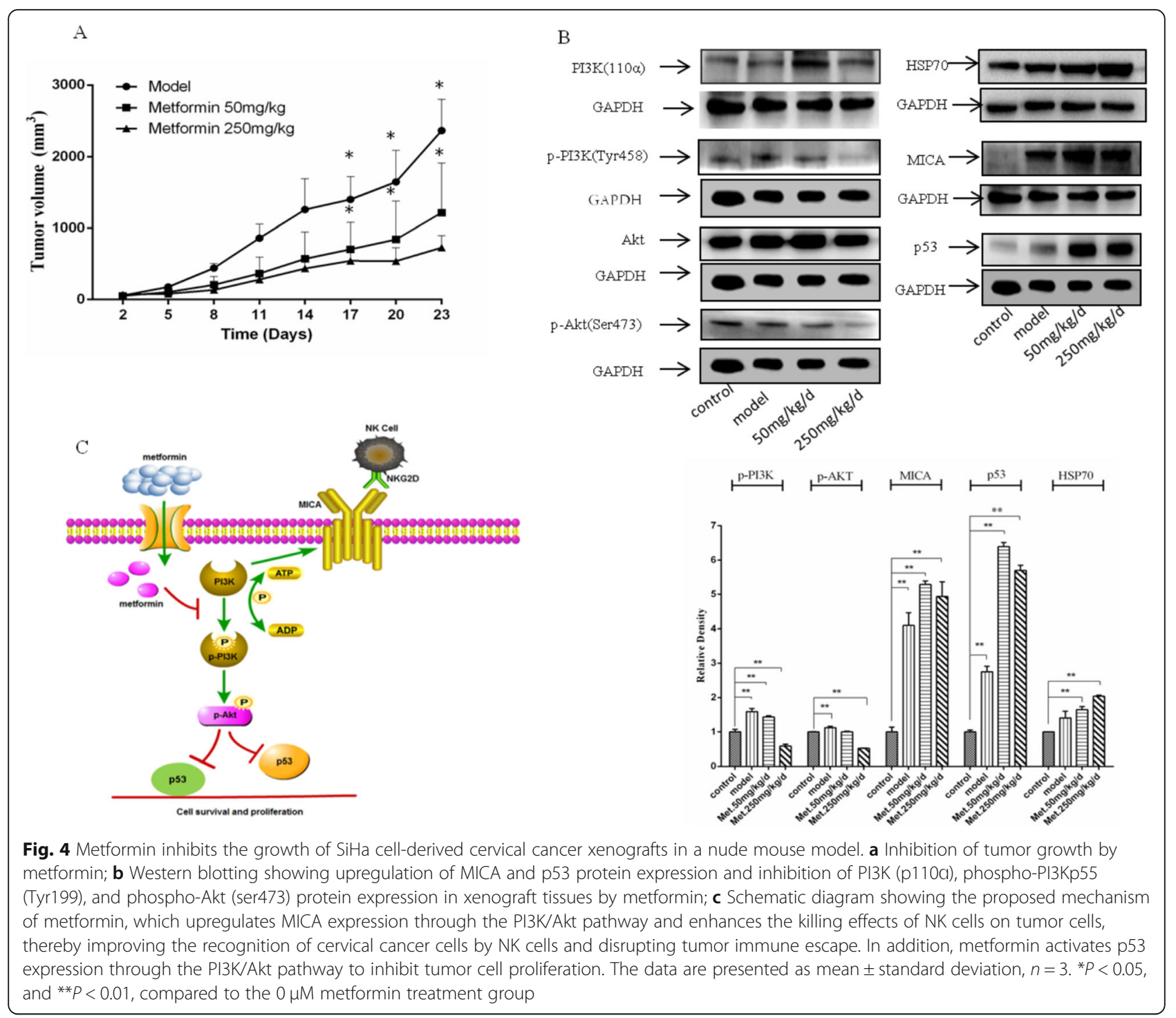

dependent kinase 1 (PDK1). Akt, also known as protein kinase $B(\mathrm{PKB})$, is an important downstream molecule of PI3K. Akt immediately attained its activated state by phosphorylation (p-Akt) and activated Akt and mTOR are indicators of poor prognosis in cervical cancer patients. They play an important role in regulating cell growth, proliferation, survival, and glucose metabolism $[56,57]$. A previous study has shown that PI3K is highly expressed in a variety of tumors, including cervical cancer [56]. When PI3K is inhibited, the corresponding expression of downstream Akt and mTOR is reduced, and the cell signaling pathway is blocked. Therefore, cell proliferation is inhibited. Although Akt is the core molecule of this signaling pathway, only few small-molecule inhibitors directly inhibit Akt by suppressing its phosphorylation. In the present study, we did not block mAbs for NKG2D and /or MICA to demonstrate the specific activity on the NKG2D receptor. However, we used
LY294002, a specific PI3K inhibitor, to block the PI3K/ Akt pathway. The results showed that combining metformin with LY294002 showed synergistic effect on upregulating MICA in cervical cancer cells. In general, combining two active molecules having the same target in a signal pathway may result in antagonistic effect, while combination of two active molecules having different targets may lead to synergistic effect [58]. That is to say, metformin directly reduced p-PI3K p85 (Tyr199) and p-Akt (ser473) levels in cervical cancer cells, which probably resulted in the antitumor effect. According with our previous study [59], metformin did not target PI3Ks or Akt.

According to the clinical application guidelines for metformin [60], the daily dose of metformin should not exceed $2000 \mathrm{mg} / \mathrm{d}$. Based on the Meeh-Rubner conversion formula and mouse and human bodyweights and specific surface areas as well as previous studies on 
tumor growth inhibition by metformin, we find the appropriate doses of metformin intraperitoneal injection to be $50-250 \mathrm{mg} / \mathrm{kg} / \mathrm{d}$. We selected low and high doses of metformin, $50 \mathrm{mg} / \mathrm{k} / \mathrm{d}$ and $250 \mathrm{mg} / \mathrm{kg} / \mathrm{d}$, respectively, which were equivalent to $384.5 \mathrm{mg} / \mathrm{d}$ and $1922.5 \mathrm{mg} / \mathrm{d}$ in human, with the high dose nearly matching the highest dose of metformin in clinical practice. This study showed that metformin significantly reduced the tumor xenograft size in the treatment groups, compared with the model group, suggesting that metformin inhibited PI3K/Akt signaling, upregulated p53 signaling, activated MICA protein expression in the tumor cells and inhibited the growth of cervical cancer xenografts in the $\mathrm{BALB} / \mathrm{c}$ nude mouse model.

\section{Conclusions}

In short, this study indicated that metformin targets both the PI3K/Akt and p53 pathways and exerts antitumor effects in the body. This study provides insights into the development of multi-target inhibitors for cervical cancer.

\section{Abbreviations}

LDH: Lactate dehydrogenase; NK cell: Natural killer cell; MICA: Histocompatibility complex class I-related chain A; PI3K: Phosphatidylinositol 3-kinase; mTORC1: Rapamycin complex 1; Bcl-1: B-cell lymphoma 2; VPA: Valproic acid; HMGA2: High-mobility group A protein 2

\section{Acknowledgements}

None.

\section{Authors' contributions}

All other authors declare no competing interests. Chenglai Xia supervised the entire work and performed the cell cultures. Zhihong He performed proliferation assays, Chang Liu performed apoptosis assays, cell cycle assays and $\mathrm{qPCR}$ assays. Jinman Chen performed lactate dehydrogenase cytotoxicity assay. Zhihong He, Chang Liu, Jinman Chen performed the western blot assay and animal experiments. Chenglai Xia, Chang Liu and Yantao Cai analyzed the data. Chenglai Xia conceived and designed the experiments and critically revised the manuscript. All authors discussed the results and contributed to manuscript writing. The author(s) read and approved the final manuscript.

\section{Funding}

This study was supported by grants from the Science and Technology Bureau of Foshan (No. FSOAA-KJ218-1301-0008) to Xia C and Foshan Medicine Dengfeng Project of China (2019-2021).

\section{Availability of data and materials}

Not applicable.

\section{Ethics approval and consent to participate}

All animal experimental protocols were approved by the Medical Ethics Committee of Southern Medical University affiliated Maternal \& Child Health Hospital of Foshan City (Guangdong Province, China).

\section{Consent for publication}

Consent for publication was obtained from the participants.

\section{Competing interests}

The authors declare that they have no conflict of interest.

\section{Author details}

${ }^{1}$ South Medical University Affiliated Maternal \& Child Health Hospital of Foshan, Foshan 528000, China. ${ }^{2}$ School of Pharmaceutical Sciences, Southern
Medical University, Guangzhou 510150, China. ${ }^{3}$ Foshan Women and Child hospital, Foshan 528000, China.

Received: 22 May 2020 Accepted: 21 June 2020

Published online: 06 July 2020

\section{References}

1. Siegel RL, Miller KD, Jemal A. Cancer statistics, 2019. CA Cancer J Clin. 2019; 69:7-34.

2. Classe JM, Rauch P, Rodier JF, Morice P, Stoeckle E, Lasry S, Houvenaeghel G, Groupe des Chirurgiens de Centre de Lutte Contre le Cancer. Surgery after concurrent chemoradiotherapy and brachytherapy for the treatment of advanced cervical cancer: morbidity and outcome: results of a multicenter study of the GCCLCC (Groupe des Chirurgiens de Centre de Lutte Contre le Cancer). Gynecol Oncol. 2006;102:523-9.

3. Joura EA, Leodolter S, Hernandez-Avila M, Wheeler CM, Perez G, Koutsky LA, Garland SM, Harper DM, Tang GW, Ferris DG, et al. Efficacy of a quadrivalent prophylactic human papillomavirus (types 6, 11, 16, and 18) L1 virus-likeparticle vaccine against high-grade vulval and vaginal lesions: a combined analysis of three randomised clinical trials. Lancet. 2007;369:1693-702.

4. Hoppe-Seyler K, Bossler F, Braun JA, Herrmann AL, Hoppe-Seyler F. The HPV E6/E7 oncogenes: key factors for viral carcinogenesis and therapeutic targets. Trends Microbiol. 2018;26:158-68.

5. Han K, Pintilie M, Lipscombe LL, Lega IC, Milosevic MF, Fyles AW. Association between metformin use and mortality after cervical Cancer in older women with diabetes. Cancer Epidemiol Biomark Prev. 2016;25:50712.

6. Wheaton WW, Weinberg SE, Hamanaka RB, Soberanes S, Sullivan LB, Anso E, Glasauer A, Dufour E, Mutlu GM, Budigner GS, et al. Metformin inhibits mitochondrial complex I of cancer cells to reduce tumorigenesis. Elife. 2014; 3:e02242.

7. Saini $N$, Yang X. Metformin as an anti-cancer agent: actions and mechanisms targeting cancer stem cells. Acta Biochim Biophys Sin Shanghai. 2018;50:133-43.

8. Xia C, Chen R, Chen J, Qi Q, Pan Y, Du L, Xiao G, Jiang S. Combining metformin and nelfinavir exhibits synergistic effects against the growth of human cervical cancer cells and xenograft in nude mice. Sci Rep. 2017;7: 43373.

9. Janku F, Yap TA, Meric-Bernstam F. Targeting the PI3K pathway in cancer: are we making headway. Nat Rev Clin Oncol. 2018;15:273-91.

10. Yang J, Nie J, Ma X, Wei Y, Peng Y, Wei X. Targeting PI3K in cancer: mechanisms and advances in clinical trials. Mol Cancer. 2019;18:26.

11. Engelman JA. Targeting PI3K signalling in cancer: opportunities, challenges and limitations. Nat Rev Cancer. 2009;9:550-62.

12. Bahrami A, Hasanzadeh M, Hassanian SM, ShahidSales S, Ghayour-Mobarhan M, Ferns GA, Avan A. The potential value of the PI3K/Akt/mTOR signaling pathway for assessing prognosis in cervical Cancer and as a target for therapy. J Cell Biochem. 2017;118:4163-9.

13. Vivier $\mathrm{E}$, Tomasello E, Baratin M, Walzer T, Ugolini S. Functions of natural killer cells. Nat Immunol. 2008:9:503-10.

14. Sami S, Höti N, Xu HM, Shen Z, Huang X. Valproic acid inhibits the growth of cervical cancer both in vitro and in vivo. J Biochem. 2008;144:357-62.

15. Shi P, Yin T, Zhou F, Cui P, Gou S, Wang C. Valproic acid sensitizes pancreatic cancer cells to natural killer cell-mediated lysis by upregulating MICA and MICB via the PI3K/Akt signaling pathway. BMC Cancer. 2014;14:370.

16. Kato N, Tanaka J, Sugita J, Toubai T, Miura Y, Ibata M, Syono Y, Ota S, Kondo $\mathrm{T}$, Asaka M, et al. Regulation of the expression of MHC class I-related chain a, B (MICA, MICB) via chromatin remodeling and its impact on the susceptibility of leukemic cells to the cytotoxicity of NKG2D-expressing cells. Leukemia. 2007;21:2103-8.

17. Chen D, Gyllensten U. MICA polymorphism: biology and importance in cancer. Carcinogenesis. 2014;35:2633-42.

18. Bere A, Tayib S, Kriek JM, Masson L, Jaumdally SZ, Barnabas SL, Carr WH, Allan $B$, Williamson AL, Denny $L$, et al. Altered phenotype and function of NK cells infiltrating human papillomavirus (HPV)-associated genital warts during HIV infection. Clin Immunol. 2014;150:210-9.

19. Malejczyk J, Malejczyk M, Urbanski A, Köck A, Jablonska S, Orth G, Luger TA. Constitutive release of IL6 by human papillomavirus type 16 (HPV16)harboring keratinocytes: a mechanism augmenting the NK-cell-mediated lysis of HPV-bearing neoplastic cells. Cell Immunol. 1991;136:155-64. 
20. Xia C, Liang S, He Z, Zhu X, Chen R, Chen J. Metformin, a first-line drug for type 2 diabetes mellitus, disrupts the MALAT1/miR-142-3p sponge to decrease invasion and migration in cervical cancer cells. Eur J Pharmacol. 2018:830:59-67.

21. Xia C, He Z, Liang S, Chen R, Xu W, Yang J, Xiao G, Jiang S. Metformin combined with nelfinavir induces SIRT3/mROS-dependent autophagy in human cervical cancer cells and xenograft in nude mice. Eur J Pharmacol. 2019:848:62-9.

22. Gao N, Cheng S, Budhraja A, Liu EH, Chen J, Chen D, Yang Z, Luo J, Shi X, Zhang Z. 3,3'-Diindolylmethane exhibits antileukemic activity in vitro and in vivo through a Akt-dependent process. PLoS One. 2012;7:e31783.

23. Branca M, Ciotti M, Giorgi C, Santini D, Di Bonito L, Costa S, Benedetto A, Bonifacio D, Di Bonito P, Paba P, et al. Up-regulation of proliferating cell nuclear antigen (PCNA) is closely associated with high-risk human papillomavirus (HPV) and progression of cervical intraepithelial neoplasia (CIN), but does not predict disease outcome in cervical cancer. Eur J Obstet Gynecol Reprod Biol. 2007;130:223-31.

24. Banerjee NS, Moore DW, Broker TR, Chow LT. Vorinostat, a pan-HDAC inhibitor, abrogates productive HPV-18 DNA amplification. Proc Natl Acad Sci U S A. 2018;115:E11138-11138E11147.

25. Hanahan D, Weinberg RA. Hallmarks of cancer: the next generation. Cell. 2011;144:646-74

26. Valletti A, Marzano F, Pesole G, Sbisà E, Tullo A. Targeting Chemoresistant tumors: could TRIM proteins-p53 Axis be a possible answer. Int J Mol Sci. 2019:20:1776.

27. Parveen A, Akash MS, Rehman K, Kyunn WW. Dual role of p21 in the progression of Cancer and its treatment. Crit Rev Eukaryot Gene Expr. 2016; 26:49-62.

28. Williams AB, Schumacher B. p53 in the DNA-damage-repair process. Cold Spring Harb Perspect Med. 2016;6:a026070.

29. Weiss-Steider B, Soto-Cruz I, Martinez-Campos CA, Mendoza-Rincon JF. Expression of MICA, MICB and NKG2D in human leukemic myelomonocytic and cervical cancer cells. J Exp Clin Cancer Res. 2011;30:37.

30. Chen JR, Lee YJ, Chen T, Wang KL, Dang CW, Chang SC, Liu HF, Yang YC. MHC class I chain-related gene a (MICA) polymorphism and the different histological types of cervical cancer. Neoplasma. 2005;52:369-73.

31. Cho H, Chung JY, Kim S, Braunschweig T, Kang TH, Kim J, Chung EJ, Hewitt SM, Kim JH. MICA/B and ULBP1 NKG2D ligands are independent predictors of good prognosis in cervical cancer. BMC Cancer. 2014;14:957.

32. Wang J, Li CD, Sun L. Recent advances in molecular mechanisms of the NKG2D pathway in hepatocellular carcinoma. Biomolecules. 2020;10:301.

33. Qi YX, Liu K, Yin J, Li L. Evaluation of short- and long-term efficacy of chemoradiotherapy for advanced cervical cancer using HSP70 protein combined with multimodal MRI. J Cell Biochem. 2018;119:3017-29.

34. Genest O, Wickner S, Doyle SM. Hsp90 and Hsp70 chaperones: collaborators in protein remodeling. J Biol Chem. 2019;294:2109-20.

35. Morán Luengo T, Mayer MP, Rüdiger S. The Hsp70-Hsp90 chaperone Cascade in protein folding. Trends Cell Biol. 2019;29:164-77.

36. Liu J, Liu J, Guo SY, Liu HL, Li SZ. HSP70 inhibitor combined with cisplatin suppresses the cervical cancer proliferation in vitro and transplanted tumor growth: an experimental study. Asian Pac J Trop Med. 2017;10:184-8.

37. Frezzato F, Raggi F, Martini V, Severin F, Trimarco V, Visentin A, Scomazzon E, Accordi B, Bresolin S, Piazza F, et al. HSP70/HSF1 axis, regulated via a PIJK/AKT pathway, is a druggable target in chronic lymphocytic leukemia. Int J Cancer. 2019;145:3089-100.

38. Schilling D, Tetzlaff F, Konrad S, Li W, Multhoff G. A hypoxia-induced decrease of either MICA/B or Hsp70 on the membrane of tumor cells mediates immune escape from NK cells. Cell Stress Chaperones. 2015;20: 139-47.

39. Barna J, Csermely P, Vellai T. Roles of heat shock factor 1 beyond the heat shock response. Cell Mol Life Sci. 2018;75:2897-916.

40. Xiao X, He Q, Lu C, Werle KD, Zhao RX, Chen J, Davis BC, Cui R, Liang J, Xu ZX. Metformin impairs the growth of liver kinase B1-intact cervical cancer cells. Gynecol Oncol. 2012;127:249-55.

41. Md Mokhtar AH, Malik IA, Abd Aziz N, Almabhouh FA, Durairajanayagam D, Singh HJ. LY294002, a PI3K pathway inhibitor, prevents leptin-induced adverse effects on spermatozoa in Sprague-Dawley rats. Andrologia. 2019; 51:e13196.

42. Hanprasertpong J, Jiamset I, Geater A, Peerawong T, Hemman W, Kornsilp S. The effect of metformin on oncological outcomes in patients with cervical Cancer with type 2 diabetes mellitus. Int J Gynecol Cancer. 2017;27:131-7.
43. Castillo-Quan JI, Blackwell TK. Metformin: restraining Nucleocytoplasmic shuttling to fight Cancer and aging. Cell. 2016;167:1670-1.

44. Wu L, Zhou B, Oshiro-Rapley N, Li M, Paulo JA, Webster CM, Mou F, Kacergis MC, Talkowski ME, Carr CE, et al. An Ancient, Unified Mechanism for Metformin Growth Inhibition in C. elegans and Cancer. Cell. 2016;167:170518.e13.

45. Kim D, Ahn BN, Kim Y, Hur DY, Yang JW, Park GB, Jang JE, Lee EJ, Kwon MJ, Kim TN, et al. High glucose with insulin induces cell cycle progression and activation of oncogenic signaling of bladder epithelial cells Cotreated with metformin and pioglitazone. J Diabetes Res. 2019;2019:2376512.

46. Zakikhani M, Dowling R, Fantus IG, Sonenberg N, Pollak M. Metformin is an AMP kinase-dependent growth inhibitor for breast cancer cells. Cancer Res. 2006;66:10269-73.

47. Yudhani RD, Astuti I, Mustofa M, Indarto D, Muthmainah M. Metformin modulates Cyclin D1 and P53 expression to inhibit cell proliferation and to induce apoptosis in cervical Cancer cell lines. Asian Pac J Cancer Prev. 2019; 20:1667-73.

48. Sui X, Xu Y, Wang $X$, Han W, Pan H, Xiao M. Metformin: a novel but controversial drug in Cancer prevention and treatment. Mol Pharm. 2015;12: 3783-91.

49. Ursini F, Russo E, Pellino G, D'Angelo S, Chiaravalloti A, De Sarro G, Manfredini R, De Giorgio R. Metformin and autoimmunity: a "new Deal" of an old drug. Front Immunol. 2018;9:1236.

50. Sousa H, Santos AM, Pinto D, Medeiros R. Is there a biological plausability for p53 codon 72 polymorphism influence on cervical cancer development. Acta Medica Port. 2011;24:127-34.

51. Frazao A, Rethacker L, Messaoudene M, Avril MF, Toubert A, Dulphy N, Caignard A. NKG2D/NKG2-ligand pathway offers new opportunities in Cancer treatment. Front Immunol. 2019;10:661.

52. Duan Q, Li H, Gao C, Zhao H, Wu S, Wu H, Wang C, Shen Q, Yin T. High Glucose Promotes Pancreatic Cancer Cells to Escape From Immune Surveillance via AMPK-Bmi1-GATA2-MICA/B Pathway. J Exp Clin Cancer Res. 2019:14:192.

53. Chen S, Yin C, Lao T, Liang D, He D, Wang C, Sang N. AMPK-HDAC5 pathway facilitates nuclear accumulation of HIF-1a and functional activation of HIF-1 by Deacetylating Hsp70 in the cytosol. Cell Cycle. 2015;14:2520-36.

54. Elsner L, Flügge PF, Lozano J, Muppala V, Eiz-Vesper B, Demiroglu SY, Malzahn D, Herrmann T, Brunner E, Bickeböller $H$, et al. The endogenous danger signals HSP70 and MICA cooperate in the activation of cytotoxic effector functions of NK cells. J Cell Mol Med. 2010;14:992-1002.

55. Kaszubowska L, Foerster J, Kwiatkowski P, Schetz D. NKT-like cells reveal higher than T lymphocytes expression of cellular protective proteins HSP70 and SOD2 and comparably increased expression of SIRT1 in the oldest seniors. Folia Histochem Cytobiol. 2018;56:231-40.

56. Jiang W, Ji M. Receptor tyrosine kinases in PI3K signaling: the therapeutic targets in cancer. Semin Cancer Biol. 2019:59:3-22.

57. Noorolyai S, Shajari N, Baghbani E, Sadreddini S, Baradaran B. The relation between PI3K/AKT signalling pathway and cancer. Gene. 2019;698:120-8.

58. Bossler F, Hoppe-Seyler K, Hoppe-Seyler F. PI3K/AKT/mTOR Signaling Regulates the Virus/Host Cell Crosstalk in HPV-Positive Cervical Cancer Cells. Int J Mol Sci. 2019;20.

59. Xia C, Yang F, He Z, Cai Y. iTRAQ-based quantitative proteomic analysis of the inhibition of cervical cancer cell invasion and migration by metformin. Biomed Pharmacother. 2020;123:109762.

60. Bjornstad P, Cree-Green M, Baumgartner A, Coe G, Reyes YG, Schäfer M, Pyle L, Regensteiner JG, Reusch JE, Nadeau KJ. Achieving ADA/ISPAD clinical guideline goals is associated with higher insulin sensitivity and cardiopulmonary fitness in adolescents with type 1 diabetes: Results from RESistance to InSulin in Type 1 ANd Type 2 diabetes (RESISTANT) and Effects of MEtformin on CardiovasculaR Function in AdoLescents with Type 1 Diabetes (EMERALD) Studies. Pediatr Diabetes. 2018;19:436-42.

\section{Publisher's Note}

Springer Nature remains neutral with regard to jurisdictional claims in published maps and institutional affiliations. 